\title{
Does Foreign Exchange Volume Activity Predict Foreign Exchange Returns? Evidence from Buy-Sell Volume in the Euro-Dollar Market
}

\author{
David Spohn \\ Correspondence: David Spohn, Independent Researcher, Lithia, Florida, USA. \\ Received: April 2, 2018 \\ doi:10.11114/afa.v4i2.3169 \\ Accepted: April 20, $2018 \quad$ Available online: April 22, 2018 \\ URL: https://doi.org/10.11114/afa.v4i2.3169
}

\begin{abstract}
This paper investigates the predictive ability of lagged buy-sell volume on current foreign exchange returns. Using novel Euro-Dollar foreign exchange market data from 2007 to 2015, we show that the buy-sell volume has an inverse correlation with current foreign exchange returns. Using conditional regression analysis, buy-sell volumes predict subsequent Euro-Dollar returns. We divide the data into two sub-samples. We use the first sub-sample to create a trading rule, and we use the second sub-sample to test the rule. After adjusting for time-varying calendar effects, we find that a profitable trading strategy exists using only buy-sell volume to predict returns.
\end{abstract}

Keywords: foreign exchange, behavioral finance, currency returns, investment

\section{Introduction}

Do market fundamentals determine foreign exchange market prices? The literature is riddled with differing opinions on price behavior and market fundamentals. While most agree that over the long-run prices should reflect fundamentals, many believe that short-term market inefficiencies provide opportunities for profit. This paper focuses on the role of non-fundamentals in short-term price setting in the world's largest financial market, the foreign exchange market with over $\$ 6$ trillion traded daily.

In seminal research, Fama (1965) introduces the idea of random fluctuation in efficient markets. However, the emerging academic literature has cast some doubt on the previously proposed random walk hypothesis and suggests that other factors may influence returns in the short run. Contrary to the Efficient Market Hypothesis (EMH), Taylor and Allen (1992) find that speculators in the foreign exchange market place a markedly higher weight on technical analysis as opposed to fundamental analysis. Sweeney (1986) finds that profits or returns are not explained by risk premia. Neely, Weller, and Ditmar (1997) conclude that economically significant out-of-sample returns using rules identified as similar to technical traders are more profitable than investing on fundamental analysis, and Marsh (2000) finds inconsistencies using Markov models in generating forecasts in the foreign exchange markets.

As most recent literature concentrating on foreign exchange revolves around profitable technical trading, there could plausibly exist other inefficiencies in the foreign exchange market that enables positive returns. Previous literature focuses on two common themes: central bank intervention (Sweeney, 1997) and noise traders (Shleifer and Summers, 1990). Extant literature indicates that central bank intervention leads to profitable returns, while other research suggests otherwise. Noise traders, on the other hand, present an interesting phenomenon. Shiller (1989) suggests that these market practioners may be using information irrationally and inefficiently to determine market positions. Can we use this footprint (i.e., buy-sell volume) to predict returns? Little is known about the impact of lagged volume on current returns in the foreign exchange markets. This paper fills this void by employing data on the foreign exchange market, more specifically on the Euro dollar/US dollar (i.e. US dollars per Euro dollars) pair to gauge the effects of lagged volume and current returns and finds that a profitable trading strategy exists using only Volume counter-intuitively.

\section{Theoretical Background and Hypothesis Development}

Volume is often thought of as the number of transactions between buyers and sellers that are exchanged over a period of time. Buyers or sellers may initiate trades. The classification of trades has become a major fundamental subject in the framework of information content of trades, order imbalance, effective spread and other areas (Menkhoff, Sarno, Schmeling, and Schrimpf, 2016). The classification of trades helps researchers in determining the differential influence of seller-initiated and buyer-initiated trades. Most previous studies use the buyer-seller classification in their analysis. Intraday databases in stock markets fail to predict trade direction. Consequently, researchers have often relied on trade 
direction algorithms in classifying transactions (Lee and Ready, 1991). Building on this research, Lee and Radhakrishna (2000) evaluate several alternative methodologies for the classification of individual trades using quota and intraday trade data utilizing a dataset of 144 firms on the New York Stock Exchange. However, behavioral finance researchers suggest that the use of such algorithms may fail to forecast correct trends in the ebbs and flows of markets, or may actually move counter-intuitively.

Behavioral finance attempts to address these issues by examining market inefficiencies, culminating in the idea that investors, thinking themselves to be rational, are actually exhibiting irrational behavior by cutting gains short and letting losses continue, as well as contributing to market phenomena, unexpected behavior, or even contrairian (Kaniel, Saar, and Titman, 2008). Schumpeter (1954) alludes to behavioral finance in his observation of the markets and their seemingly irrational behavior, concluding that psychologists may help in explaining this oddity. Martin Weber (1999) suggests that a combination of individual behavior and financial theory should be used together. There are many examples throughout the literature that imply behavioral finance is relevant. Following the underpinnings of behavioral finance, it is reasonable to assume that there is a finite amount of money to be invested over any extended period of time. Given a finite amount of money to be invested, there is also a finite number of investors to take positions within any market over the same period of time. To accommodate both buyers and sellers in this type of environment, markets may not be as efficient as proposed, at least in the short-term. Thus, we expect to find some inconsistencies within the volume of trades that affect returns.

Given the contextual lens presented above, we examine the Euro dollar/US dollar (EURUSD) currency pairing within the foreign exchange (spot) market. Prior studies focus on the correlation between price and volume (Harris, 1987; Muller, Dacorogna, Olsen, Pictet, Shwarz, and Morgenegg, 1990), but do not specifically focus on or analyze the difference between Buy Volume and Sell Volume and its impact on FX Returns. Thus, we focus on volume and returns, while expecting to see an inverse relationship in-line with behavioral finance (more specifically, investor irrationality) and hypothesize the following:

Hypothesis 1. As lagged FX Buy Volume increases relative to lagged Sell Volume, current FX Returns move down, or a negative relationship between prior period Buy Volume and next period Returns.

While other studies focus on different metrics to analyze the impact on foreign exchange returns (Sweeney, 1986; Neely, Weller, and Ditmar, 1997), our interest lies in whether or not Buy Volume and Sell Volume impact Returns. If there is an impact on Returns, we are interested in knowing what impact as well as the profitability of that relationship. Previous works focusing on rules-based foreign exchange trading strategies report substantial profits (Dooley and Shafter, 1983; Sweeney, 1986) even after transaction costs are calculated.

Hypothesis 2. Using only lagged Buy Volume and Sell Volume, a trading strategy can be devised to enter and exit a trade and remain profitable once reasonable transaction costs have been factored.

In our analysis, we aim to look at lagged Buy Volume and lagged Sell Volume to determine if there is a negative relationship that impacts current Returns (Hypothesis 1). If the hypothesized relationship exists, our goal is to determine how profitable (after transaction costs) the proposed method is in trading the EURUSD during the 2007-2015 period (Hypothesis 2).

This paper enriches our understanding of short run foreign exchange market dynamics through its testing of non-fundamental volume effects.

\section{Data and Methodology}

\subsection{Data}

We gather Euro - US dollar (EURUSD) spot currency daily data from Forex Capital Markets (FXCM). Our data set includes the date, Mid-Price, Buy Volume, and Sell Volume on EURUSD from January 3, 2007-June 4, 2015 (i.e., 2,087 daily observations). Table 1 provides descriptive statistics on these data, including the sample mean, median, standard deviation, minimum, and maximum values of each respective variable.

Table 1. Descriptive Statistics

\begin{tabular}{llllll}
\hline & Mean & Median & Std & Min & Max \\
\cline { 2 - 6 } Variables & & & & & \\
Mid-Price & 1.352797 & 1.35099 & 0.09614 & 1.04964 & 1.599 \\
Buy Volume & 5788.41 & 5505 & 2739.706 & 1333 & 16830 \\
Sell Volume & 8140.14 & 7354 & 4324.309 & 1687 & 26605 \\
\hline
\end{tabular}

This table presents summary statistics on daily EUR-USD spot exchange rates from Forex Capital Markets (FXCM) over January 3, 2007 through June 4, 2015 sample period. The overall sample includes 2,087 daily observations. The Mid-Price is the mid-point between the Bid and Ask price. Buy Volume is the number of buy orders initiated. Sell 
Volume is the number of sell orders initiated.

Using daily volume (Froot and Ramadorai, 2005) produces more accurate confidence bands with relative consistency (Anderson and Bollerslev, 1997). Thus, we define Buy Volume as the number of hourly buy initiated orders, which we accumulate on a daily basis to obtain a daily Buy Volume. Sell Volume is defined as the number of hourly sell initiated orders. The hourly data is again accumulated to obtain a daily total Sell Volume. The daily Mid-Point is the middle point between the daily Bid and Ask price of the spot Euro-Dollar exchange rate. The Euro-Dollar Return is the growth rate of the daily exchange rate from period 1 to period 2, calculated by (Mid-Point2/Mid-Point1)-1.

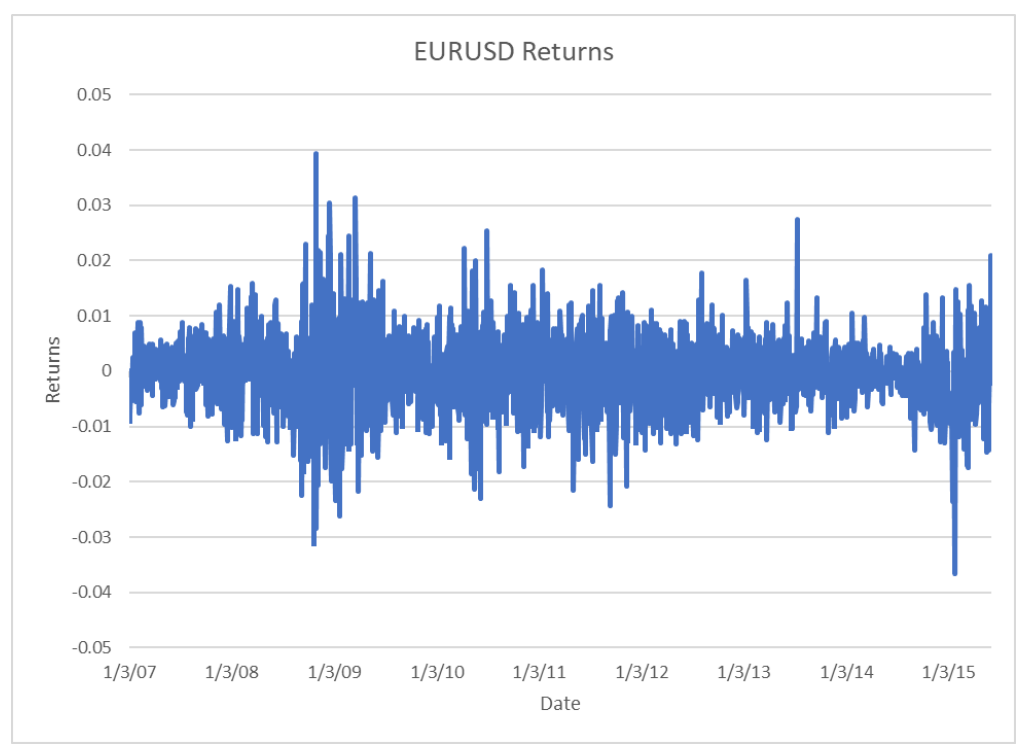

Figure 1. EURUSD Returns

This figure reports the EURUSD Returns from January 3, 2007 through June 4, 2015. Returns are calculated as $R_{t}=\frac{M P_{t}}{M P}{ }_{t-1}-1$ where the currency returns from day $t-1$ to $t$ are computed. $R_{t}$ is the spot exchange rate at the daily close where the midpoint $t$ is $M P_{t}$, and the spot exchange rate at the daily close midpoint $t-1$ is $M P_{t-1}$.

Looking at Table 1, we see that the sample mean of the daily mid-price of the EURUSD is 1.3528 and has a standard deviation of .0961. The maximum and minimum mid-price values of 1.599 and 1.0496 do not suggest the presence of sharp data discontinuities, and are within expectations of daily fluctuations over the 8-year sample period.

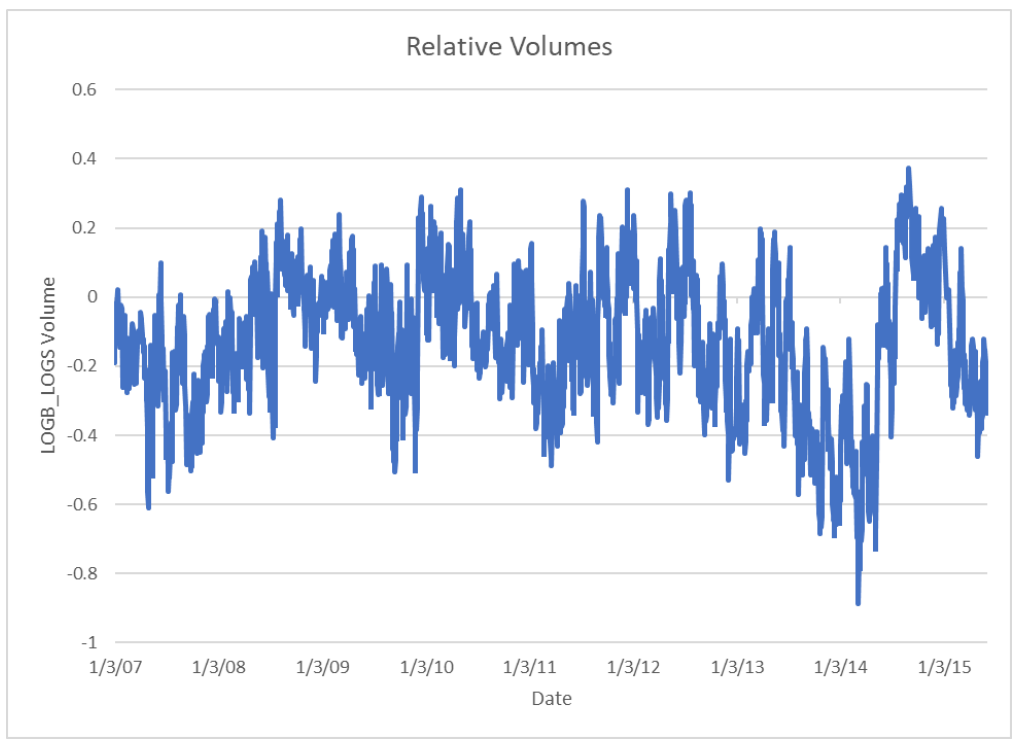

Figure 2. Relative volumes 
This figure represents the Relative Volume in the EURUSD from January 3, 2007 through June 4, 2015. The Volume (LOGB_LOGS) is calculated by taking the $\log$ transformation of the previous day Buy Volume minus the log transformation of the previous day Sell Volume.

The average buy volume is 5788.41 (in millions) and has a standard deviation of 2739.71 . The maximum and minimum buy volumes are 16830 and 1333 , while the average sell volume is 8140.14 with maximum and minimum sell volumes of 26605 and 1686, respectively. The descriptive statistics for buy and sell volumes in Table 1 are consistent with those reported in the previous literature (Wasserfallen, 1989; Muller, Dacorogna, Olsen, Prictet, Schwarz, and Morgenegg, 1990; Dacorogna, Muller, Nagler, Olsen, and Pictet, 1993).

\subsection{Methodology}

In our analysis, we first provide some basic correlations to show the relationship between spot Euro-Dollar returns and Buy versus Sell Volumes. We then run regressions to capture the lead-lag relation between Euro-Dollar returns and Buy versus Sell Volumes. Our methodology follows Llorente, Michaely, Saar, and Wang (2002) as well as Chan and Fong (2000) in capturing the lead-lag effects. We define daily Buy Volume as:

$$
V_{B, t}=\sum(h 0+h 1+\cdots h 23)_{B, t-1}
$$

where $V_{B, t}$ is the daily volume expressed as buyer's positions $B$ at day $t$, and $h 0$ through $h 23$ is the hourly volume of buyer's positions $B$ at day $t$.

Consistent with the previous definition of daily Buy Volume, we define the daily Sell Volume as:

$$
V_{S, t}=\sum(h 0+h 1+\cdots h 23)_{S, t-1}
$$

where $V_{S, t}$ is the daily volume expressed as seller's positions $S$ at day $t$, and $h 0$ through $h 23$ is the hourly volume of seller's positions $S$ at day $t$.

Based on the previous studies, we use Returns and Volume (Buy and Sell). We utilize the Euro-Dollar (spot Forex) to compare and contrast the impact of volume on returns, and define daily Returns as:

$$
R_{t}={\frac{M P_{t}}{M P}}_{t-1}-1
$$

where the currency returns from day $t-1$ to $t$ are computed. $R_{t}$ is the spot exchange rate at the daily close where the midpoint $t$ is $M P_{t}$, and the spot exchange rate at the daily close midpoint $t-1$ is $M P_{t-1}$.

We do a correlation analysis between the previous day's Buy Volume minus the previous day's Sell Volume and current Returns (Hypothesis 1). In line with Fama (1984) and Muller, Dacorogna, Olsen, Pictet, Shwarz, and Morgenegg (1990), we take the log transformation of the previous day Buy Volume minus the log transformation of the previous day Sell Volume (LOGB_LOGS) to scale the data and reduce the right tail of the distribution given the slight positive skew.

Since we are interested in whether an increase in the previous day's Buy Volume minus the previous day's Sell Volume is inversely related with current Returns (meaning the more buyers that enter the market relative to sellers, the lower the price falls and vice versa), we look at Pearson's correlation coefficient. The confidence interval is the boundary between which the population value could be zero (no effect at all). We look at whether the confidence interval crosses below zero to above zero (or vice versa) to determine whether there is a genuine effect on the population (or an inverse relationship between the number of Buyers minus Sellers and Returns).

Since calendar time effects are common in foreign exchange markets, we also do our analysis of lagged volume on current Euro-Dollar returns at various calendar intervals: Daily, Mondays (only), Tuesdays (only), Wednesdays (only), Thursdays (only), Fridays (only), Weekends (Friday thru Sunday only), Beginning of the Day (0000-0759), Middle of the Day (0800-1559), End of Day (1600-2359), and Non-Farm Payroll days (Thursday-Friday). We include Non-Farm Payrolls to capture the effect of a fundamental news announcement every month.

In our analysis, we create 'Buckets' where each of the Volume is defined as:

Bucket 1: Buy Volume - Sell Volume $>0$

Bucket 2: Buy Volume - Sell Volume $=0(300<$ Buy Volume-Sell Volume $>-300)$

Bucket 3: Buy Volume - Sell Volume $<0$

These buckets capture potential FX pressure through the extent to which Buy Volume exceeds Sell Volume (Bucket 1), Buy and Sell volumes are essentially in balance (Bucket 2), and Sell Volume exceeds Buy Volume. Besides capturing FX pressure, we expect ex-ante to see further evidence of the inverse relationship (Hypothesis 1) where excessive Buy Volume leads to negative returns, and excessive Sell Volume leads to positive returns. On completion of the correlation analysis between the log transformation of the previous day Buy Volume minus the log transformation of the previous 
day Sell Volume and current Returns, we follow previous studies in regressing the log transformation of the previous day Buy Volume minus the log transformation of the previous day Sell Volume against current Returns utilizing the same timeframes and the created buckets within each timeframe (Hypothesis 2). We split the sample in half to see how profitable the trading rule (or regression) works in two sub-periods. The first sub-period (approximately 4 years) is used to create the trading rule, while the second sub-period (approximately 4 years) is used to test profitability.

In line with Lyons (1995), we take into consideration the transaction costs associated with entering and exiting a trade. Thus, we calculate the transaction costs as:

$$
C_{\text {Mpt }}= \pm 1.4_{\text {pips }}
$$

where $C_{M p t}$ is the transaction cost of the midpoint of the daily closing price equals plus or minus 1.4 pips or daily closing price plus or minus .00014 depending on the trading strategy's intended direction. If our strategy dictates a 'Buy', we add .00014 pips to cover the average spread, while a 'Sell' would indicate subtracting .00014 from the daily close midpoint price.

In both the correlation analysis and regression analysis, we bootstrap confidence intervals (Brock, Lakonishok, and LeBaron, 1992) for the correlation coefficients (Andersen and Bollerslev, 1997) and regressions to address potential biases and select confidence intervals utilizing bias corrected accelerated (BCa).

\section{Empirical Results}

\subsection{Correlation Results}

We analyze the data on the Euro-Dollar by taking the log transformation of the previous period's Buy Volume minus the log transformation of the previous period's Sell Volume (LOGB_LOGS) to determine the directional relationship with current Returns and selectively look at Pearson's correlation coefficient. Our analysis includes LOGB_LOGS and Returns. Table 2 provides the correlation analysis including the Pearson's correlation coefficient on the defined time periods: Daily, Mondays (only), Tuesdays (only), Wednesdays (only), Thursdays (only), Fridays (only), Weekends (Friday thru Sunday only), Beginning of the Day (0000-0759), Middle of the Day (0800-1559), End of Day (1600-2359), and Non-Farm Payroll days (Thursday-Friday).

Table 2. Correlation Analysis for LOGB_LOGS

\begin{tabular}{|c|c|c|c|c|c|}
\hline \multicolumn{2}{|l|}{ Period } & Overall & Bucket 1 & Bucket 2 & Bucket 3 \\
\hline \multirow{2}{*}{ Daily } & & Returns & Returns & Returns & Returns \\
\hline & LOGB_LOGS & $\begin{array}{c}-.326 * * \\
(-.357,-.295)\end{array}$ & $\begin{array}{c}-.218 * * \\
(-.299,-.131)\end{array}$ & $\begin{array}{c}-.151^{*} \\
(-.300, .001)\end{array}$ & $\begin{array}{c}-.114 * * \\
(-.159,-.072)\end{array}$ \\
\hline Monday & LOGB_LOGS & $\begin{array}{c}-.483 * * \\
(-.544,-.422)\end{array}$ & $\begin{array}{c}-.108 \\
(-.307, .067)\end{array}$ & $\begin{array}{c}-.300 \\
(-.571, .025)\end{array}$ & $\begin{array}{c}-.160 * * \\
(-.256,-.066)\end{array}$ \\
\hline Tuesday & LOGB_LOGS & $\begin{array}{c}-.424 * * \\
(-.495,-.356)\end{array}$ & $\begin{array}{c}-.297 * * \\
(-.471,-.126)\end{array}$ & $\begin{array}{c}-.060 \\
(-.383, .309)\end{array}$ & $\begin{array}{c}-.124 * \\
(-.223,-.035)\end{array}$ \\
\hline Wednesday & LOGB_LOGS & $\begin{array}{c}-.483^{* *} \\
(-.558,-.403)\end{array}$ & $\begin{array}{c}-.274 * * \\
(-.453,-.092)\end{array}$ & $\begin{array}{c}-.179 \\
(-.465, .189)\end{array}$ & $\begin{array}{c}-.260 * * \\
(-.351,-.167)\end{array}$ \\
\hline Thursday & LOGB_LOGS & $\begin{array}{c}-.450 * * \\
(-.534,-.365)\end{array}$ & $\begin{array}{c}-.112 \\
(-.307, .069)\end{array}$ & $\begin{array}{c}-.141 \\
(-.429, .277)\end{array}$ & $\begin{array}{c}-.224 * * \\
(-.322,-.126)\end{array}$ \\
\hline Friday & LOGB_LOGS & $\begin{array}{c}-.464 * * \\
(-.528,-.394)\end{array}$ & $\begin{array}{c}-.170 \\
(-.362, .025)\end{array}$ & $\begin{array}{c}-.298 \\
(-.575, .073)\end{array}$ & $\begin{array}{c}-.225^{* *} \\
(-.322,-.134)\end{array}$ \\
\hline Weekend & LOGB_LOGS & $\begin{array}{c}-.391 * * \\
(-.441,-.339)\end{array}$ & $\begin{array}{c}-.189 * * \\
(-.325,-.055)\end{array}$ & $\begin{array}{c}-.211 \\
(-.437, .033)\end{array}$ & $\begin{array}{c}-.136^{* *} \\
(-.213,-.058)\end{array}$ \\
\hline $\begin{array}{l}\text { Beginning } \\
\text { Of Day }\end{array}$ & LOGB_LOGS & $\begin{array}{c}-.106^{* *} \\
(-.118,-.093)\end{array}$ & $\begin{array}{c}-.070 * * \\
(-.103,,-.038)\end{array}$ & $\begin{array}{c}-.061 * \\
(-.111, .-008)\end{array}$ & $\begin{array}{c}-.033^{* *} \\
(-.049,-.018)\end{array}$ \\
\hline $\begin{array}{l}\text { Middle } \\
\text { Of Day }\end{array}$ & LOGB_LOGS & $\begin{array}{c}-.104 * * \\
(-.117,-.093)\end{array}$ & $\begin{array}{c}-.064 * * \\
(-.091,-.037)\end{array}$ & $\begin{array}{c}-.068 * * \\
(-. .122,-.012)\end{array}$ & $\begin{array}{c}-.036 * * \\
(-.052,-.019)\end{array}$ \\
\hline $\begin{array}{l}\text { End } \\
\text { Of Day }\end{array}$ & LOGB_LOGS & $\begin{array}{c}-.122 * * \\
(-.135,-.109)\end{array}$ & $\begin{array}{c}-.067 * * \\
(-.098,-.035)\end{array}$ & $\begin{array}{c}-.038 \\
(-.094, .019)\end{array}$ & $\begin{array}{c}-.041 * * \\
(-.056,-.024)\end{array}$ \\
\hline $\begin{array}{l}\text { Non-Farm } \\
\text { Payrolls }\end{array}$ & LOGB_LOGS & $\begin{array}{c}-.421 * * \\
(-.504,-.331)\end{array}$ & $\begin{array}{c}-.075 \\
(-.366, .183)\end{array}$ & $\begin{array}{c}-.349 \\
(-.817 . .253)\end{array}$ & $\begin{array}{c}-.260 * * \\
(-.400,-.123)\end{array}$ \\
\hline
\end{tabular}


This table reports Pearson's correlation coefficient for various intervals and within three predefined buckets. The buckets are defined as follows: Bucket $1=$ LOGB-LOGS $>0$, Bucket $2=$ LOGB-LOGS $=0$ (300<LOGB-LOGS>-300), and Bucket $3=$ LOGB-LOGS < 0. LOGB_LOGS is defined as the log transformation of the previous day lag Buy Volume minus the previous day lag Sell Volume. Returns are defined as the difference between the price from period 1 to period 2 and then subtracting 1 from the difference. Each period is defined as: Daily (from day-to-day), Mondays (only), Tuesdays (only), Wednesdays (only), Thursdays (only), Fridays (only), Weekends (Friday to Sunday only), Beginning of the Day (0000-0759 only), Middle of the Day (0800-1559 only), End of the Day (1600-2359 only), and Non-Farm Payrolls (Thursday-Friday only) on days of release. Significance levels are reported as: *,**, ***.05, .01 and .001 levels, respectively. Bias corrected accelerated bootstrap 95\% Confidence Intervals reported in the parentheses.

Table 2 summarizes the Pearson's correlation coefficient for the various intervals. We separate each interval into the overall correlation considering all of the data holistically, then the predefined buckets and report the Pearson's correlation coefficient for each period. In line with expectations of Hypothesis 1, we find the correlation between Returns and LOGB_LOGS as negative, or inversely correlated as is evidenced by the Pearson's correlation coefficient. All periods in the Overall column are negative, and significant at the $\mathrm{p}<.01$ level. Within Buckets 1 and 3 , we find that all periods are negative and most are significant at the $\mathrm{p}<.01$. As expected, we find that Bucket 2 is more sporadic (buy-sell volume balance), while only 3 time periods are significant (Daily at $\mathrm{p}<.05$, Beginning of the Day at $\mathrm{p}<.05$, and Middle of the Day at $p<.01$ ). The Daily at $p<.05$ is significant but is not valid, as the Pearson's correlation coefficient crosses from below zero to above zero. The Beginning of the Day at $\mathrm{p}<.05$ and the Middle of the Day at $\mathrm{p}$ $<.01$ fall in line with previous literature, indicating accumulated volume contributes to price dynamic changes (Khemiri, 2012).

The calendar effects are stable in the Overall column as they are negative and significant at the $p<.01$ level throughout the data set. However, we find some anomalies within the sub-sample periods and buckets. Mondays, Thursdays, Fridays and Non-Farm Payrolls are not significant in Bucket 1 but are significant in Bucket 3. This implies that there might be some momentum effects within those specific timeframes when taken in isolation.

\subsection{Regression Results}

We again analyze the data on the Euro-Dollar for the various intervals within the predefined buckets by first regressing the Returns against the log transformation of the previous day's Buy Volume minus the log transformation of the previous period's Sell Volume (LOGB_LOGS). The regression values include the following defined time periods: Daily, Mondays (only), Tuesdays (only), Wednesdays (only), Thursdays (only), Fridays (only), Weekends (Friday thru Sunday only), Beginning of the Day (0000-0759), Middle of the Day (0800-1559), End of Day (1600-2359), and Non-Farm Payroll days (Thursday-Friday). 
Table 3. Regression Analysis for LOGB_LOGS

\begin{tabular}{|c|c|c|c|c|c|}
\hline \multirow{2}{*}{\multicolumn{2}{|c|}{ Period }} & Overall & Bucket 1 & Bucket 2 & Bucket 3 \\
\hline & & & & & \\
\hline Daily & $\begin{array}{l}\text { Constant } \\
\text { Predictor } \\
\text { Model } \\
\text { Predicted Y }\end{array}$ & $\begin{array}{l}-.002 * * * \\
-.011 * * * \\
Y=-.011 x+-.002 \\
-.013\end{array}$ & $\begin{array}{l}-.002 * \\
-.019 * * * \\
Y=-.019 x+-.002 \\
-.021\end{array}$ & $\begin{array}{l}-.001^{*} \\
-.063^{*} \\
Y=-.063 x+-.001 \\
-.064\end{array}$ & $\begin{array}{l}.000 \\
-.005 * * * \\
Y=-.005 x+.000 \\
-.005\end{array}$ \\
\hline Mondays & $\begin{array}{l}\text { Constant } \\
\text { Predictor } \\
\text { Model } \\
\text { Predicted Y }\end{array}$ & $\begin{array}{l}-.005^{* * * *} \\
-.036^{* * *} * \\
\mathrm{Y}=-.036 \mathrm{x}+-.005 \\
-.041\end{array}$ & $\begin{array}{l}-.011 * * * \\
-.018 \\
Y=-.018 x+-.011 \\
-.029\end{array}$ & $\begin{array}{l}-.007 * * \\
-.202 * \\
Y=-.202 x+-.007 \\
-.209\end{array}$ & $\begin{array}{l}.002 \\
-.013 * * \\
\mathrm{Y}=-.013 \mathrm{x}+.002 \\
-.011\end{array}$ \\
\hline Tuesdays & $\begin{array}{l}\text { Constant } \\
\text { Predictor } \\
\text { Model } \\
\text { Predicted Y }\end{array}$ & $\begin{array}{l}-.004 * * * \\
-.032 * * * \\
Y=-.032 x+-.004 \\
-.036\end{array}$ & $\begin{array}{l}-.005 * \\
-.049 * * \\
Y=-.049 x+-.005 \\
-.054\end{array}$ & $\begin{array}{l}-.009 * * * \\
-.053 \\
Y=-.053 x+-.009 \\
-.062\end{array}$ & $\begin{array}{l}.002 \\
-.011 * \\
Y=-.011 x+.002 \\
-.009\end{array}$ \\
\hline Wednesdays & $\begin{array}{l}\text { Constant } \\
\text { Predictor } \\
\text { Model } \\
\text { Predicted Y }\end{array}$ & $\begin{array}{l}-.005 * * * \\
-.035 * * * \\
Y=-.035 x+-.005 \\
-.040\end{array}$ & $\begin{array}{l}-.007 * * \\
-.036 * * * \\
Y=-.036 x+-.007 \\
-.043\end{array}$ & $\begin{array}{l}-.006^{*} \\
-.180 \\
Y=-.180 x+-.006 \\
-.186\end{array}$ & $\begin{array}{l}-.001 \\
-.021 * * * \\
\mathrm{Y}=-.021 \mathrm{x}+-.001 \\
-.022\end{array}$ \\
\hline Thursdays & $\begin{array}{l}\text { Constant } \\
\text { Predictor } \\
\text { Model } \\
\text { Predicted Y }\end{array}$ & $\begin{array}{l}-.005 * * * \\
-.035^{* * *} \\
Y=-.035 x+-.005 \\
-.040\end{array}$ & $\begin{array}{l}-.010 * * * \\
-.016 \\
Y=-.016 x+-.010 \\
-.026\end{array}$ & $\begin{array}{l}-.007 \\
-.186 \\
Y=-.186 x+-.007 \\
-.193\end{array}$ & $\begin{array}{l}-.0001 \\
-.019 * * * \\
Y=-.019 x+-.0001 \\
-.019\end{array}$ \\
\hline Fridays & $\begin{array}{l}\text { Constant } \\
\text { Predictor } \\
\text { Model } \\
\text { Predicted Y }\end{array}$ & $\begin{array}{l}-.005 * * * \\
-.033 * * * \\
Y=-.033 x+-.005 \\
-.038\end{array}$ & $\begin{array}{l}-.008 * \\
-.023 \\
Y=-.023 x+-.008 \\
-.031\end{array}$ & $\begin{array}{l}-.006^{*} \\
-.261 \\
Y=-.261 x+-.006 \\
-.267\end{array}$ & $\begin{array}{l}.000 \\
-.018 * * * \\
Y=-.018 x+.000 \\
-.018\end{array}$ \\
\hline Weekends & $\begin{array}{l}\text { Constant } \\
\text { Predictor } \\
\text { Model } \\
\text { Predicted Y }\end{array}$ & $\begin{array}{l}-.003 * * * \\
-.021 * * * \\
\mathrm{Y}=-.021 \mathrm{x}+-.003 \\
-.024\end{array}$ & $\begin{array}{l}-.005^{* * * *} \\
-.024 * * \\
Y=-.024 \mathrm{x}+-.005 \\
-.029\end{array}$ & $\begin{array}{l}-.003 * \\
-.127 \\
Y=-.127 x+-.003 \\
-.130\end{array}$ & $\begin{array}{l}.001 \\
-.008 * * * \\
\mathrm{Y}=-.008 \mathrm{x}+.001 \\
-.007\end{array}$ \\
\hline $\begin{array}{l}\text { Beginning } \\
\text { Of Day }\end{array}$ & $\begin{array}{l}\text { Constant } \\
\text { Predictor } \\
\text { Model } \\
\text { Predicted Y }\end{array}$ & $\begin{array}{l}.000 * * * \\
-.001 * * * \\
\mathrm{Y}=-.001 \mathrm{x}+.000 \\
-.001\end{array}$ & $\begin{array}{l}.000 * \\
-.002 * * * \\
\mathrm{Y}=-.002 \mathrm{x}+.000 \\
-.002\end{array}$ & $\begin{array}{l}.000 \\
-.01 * * \\
Y=-.01 \mathrm{x}+.000 \\
-.01\end{array}$ & $\begin{array}{l}.0001 \\
.000 * * * \\
\mathrm{Y}=.000 \mathrm{x}+.0001 \\
.000\end{array}$ \\
\hline $\begin{array}{l}\text { Middle } \\
\text { Of Day }\end{array}$ & $\begin{array}{l}\text { Constant } \\
\text { Predictor } \\
\text { Model } \\
\text { Predicted Y }\end{array}$ & $\begin{array}{l}.000 * * * \\
-.001 * * * \\
\mathrm{Y}=-.001 \mathrm{x}+.000 \\
-.001\end{array}$ & $\begin{array}{l}.000 * \\
-.002 * * * \\
\mathrm{Y}=-.002 \mathrm{x}+.000 \\
-.002\end{array}$ & $\begin{array}{l}.000 \\
-.01 * * \\
\mathrm{Y}=-.01 \mathrm{x}+.000 \\
-.010\end{array}$ & $\begin{array}{l}.0001 \\
.000 * * * \\
\mathrm{Y}=.000 \mathrm{x}+.0001 \\
.000\end{array}$ \\
\hline $\begin{array}{l}\text { End } \\
\text { Of Day }\end{array}$ & $\begin{array}{l}\text { Constant } \\
\text { Predictor } \\
\text { Model } \\
\text { Predicted Y }\end{array}$ & $\begin{array}{l}.000 * * * \\
-.001 * * * \\
\mathrm{Y}=-.001 \mathrm{x}+.000 \\
-.001\end{array}$ & $\begin{array}{l}.000 * * \\
-.002 * * * \\
\mathrm{Y}=-.002 \mathrm{x}+.000 \\
-.002\end{array}$ & $\begin{array}{l}.000^{*} \\
-.005 \\
Y=-.005 x+.000 \\
-.005\end{array}$ & $\begin{array}{l}.0001 \\
-.001 * * * \\
Y=-.001 \mathrm{x}+.0001 \\
-.001\end{array}$ \\
\hline $\begin{array}{l}\text { Non-Farm } \\
\text { Payrolls }\end{array}$ & $\begin{array}{l}\text { Constant } \\
\text { Predictor } \\
\text { Model } \\
\text { Predicted Y }\end{array}$ & $\begin{array}{l}-.006 * * * \\
-.047 * * * \\
Y=-.047 x+-.006 \\
-.053\end{array}$ & $\begin{array}{l}-.013 * \\
-.017 \\
Y=-.017 x+-.013 \\
-.030\end{array}$ & $\begin{array}{l}-.008 \\
-.528 \\
Y=-.528 x+-.008 \\
-.536\end{array}$ & $\begin{array}{l}-.003 \\
-.035^{* *} \\
Y=-.035 x+-.003 \\
-.038\end{array}$ \\
\hline
\end{tabular}

This table reports the regression analysis for various intervals and within three predefined buckets. The reported values for the Constant (Intercept), Predictor (gradient), Model (Regression Line), and Predicted Y are shown. The buckets are 
defined as follows: Bucket $1=$ LOGB-LOGS $>0$, Bucket $2=$ LOGB-LOGS $=0$ (300<LOGB-LOGS>-300), and Bucket $3=$ LOGB-LOGS < 0. LOGB_LOGS (independent variable) is defined as the log transformation of the previous day lag Buy Volume minus the previous day lag Sell Volume. Returns (dependent variable) are defined as the difference between the price from period 1 to period 2 and then subtracting 1 from the difference. Each period is defined as: Daily (from day-to-day), Mondays (only), Tuesdays (only), Wednesdays (only), Thursdays (only), Fridays (only), Weekends (Friday to Sunday only), Beginning of the Day (0000-0759 only), Middle of the Day (0800-1559 only), End of the Day (1600-2359 only), and Non-Farm Payrolls (Thursday-Friday only) on days of release. Significance levels are reported as: *,*****.05, .01 and .001 levels, respectively.

Table 3 summarizes the values for the Constant (Intercept), Predictor (gradient), Model (Regression Line), and the Predicted value of $\mathrm{Y}$ for the regression between Returns and the log transformation of the previous day's Buy Volume minus the log transformation of the previous day's Sell Volume (LOGB_LOGS). We separate each interval into the overall regression considering all of the data, then within the predefined buckets and report the values.

We find regressions between Returns and LOGB_LOGS are negative, with one exception (Middle of the Day, Bucket 3). All regressions in the Overall column are negative, and significant at the $\mathrm{p}<.001$ level. Predicted values range from -.001 to -.053 . Within Bucket 1, we find that all predicted values are negative, and most are significant ( 7 out of 11 reported periods of the Constant value and Predictor value) at acceptable levels. Bucket 2 (volume balance) is more unstable, as all predicted values are negative while only 2 out of the 11 reported periods (Constant value and Predictor value) are significant (Daily and Mondays). We find that Bucket 3 has mostly negative predicted values with the one exception being Middle of the Day. None of Bucket 3 predicted values are significant. As with the correlation analysis (above), we find relatively the same reflection in results in the calendar effects within the same sub-samples.

\subsection{Trading Strategy Tests}

We test our trading strategy by separating the data set into two sub-groups. We use the first sub-group (approximately 4 years) to create the trading strategy, and then utilize the second sub-group (approximately 4 years) to test the strategy for profitability. We use the Overall period of the Daily data set, as it is more consistently at levels of significance in both the correlation analyses, as well as the regression analyses. The baseline model we estimate over the first sub-group is:

$$
Y_{i, t}=\alpha_{i}+\beta_{1} L O G B_{-} L O G S
$$

where $\mathrm{Y}$ is our dependent variable of interest (or Signal). LOGB_LOGS is the independent variable, defined as the log transformation of the previous day's Buy Volume minus the log transformation of the previous day's Sell Volume. $\alpha_{i}$ is the constant (intercept).

We create a trading strategy where we sell if the value of $Y_{i, t}$ is less than 0 or buy if the value of $Y_{i, t}$ is greater than 0 . Utilizing the strategy over the second sub-group, we find the profitability of the daily strategy yields in excess of 5000 pips after transaction costs (defined in Eq. (4)), thus supporting Hypothesis 2.

\section{Additional Robustness Tests}

In this section, we discuss some potential issues and our attempts to address them in greater detail. Our main variable of interest is Volume and its correlation to Returns. Besides Volume and Returns, there are many factors involved with the relevant pricing of currencies and the subsequent profitability of trading. However, momentum effects have been well documented (Engel and Hamilton, 1990; Okunev and White, 2003; Chiang and Jiang, 1995). In order to determine if we are capturing some of the momentum effects, we include a lagged foreign exchange returns variable on the right-hand side of the regression as a control variable, and do some sub-period analysis tests. Our regression specification becomes:

$$
Y_{i, t}=\alpha_{i}+\beta_{1} L O G B_{-} L O G S+\beta_{2} \text { LagFXReturns }
$$

where $\mathrm{Y}$ is our dependent variable of interest (or Signal). LOGB_LOGS is again our variable of interest, defined as the $\log$ transformation of the previous day's Buy Volume minus the log transformation of the previous day's Sell Volume. LagFXReturns is a control variable and defined as the previous period Return, and $\alpha_{i}$ is the constant (intercept). 
Table 4. Regression Analysis for LOGB_LOGS with Lag FX Returns

\begin{tabular}{|c|c|c|c|c|c|}
\hline & & Overall & Bucket 1 & Bucket 2 & Bucket 3 \\
\hline \multicolumn{6}{|l|}{ Period } \\
\hline \multirow[t]{6}{*}{ Daily } & Constant & $-.002 * * *$ & $-.002 * *$ & -.001 & .000 \\
\hline & Predictor & $-.011 * * *$ & $-.020 * * *$ & -.066 & $-.005 * * *$ \\
\hline & Lag $\quad F X$ & $-.060 * *$ & $-.166^{* * *}$ & -.014 & -.061 \\
\hline & Returns & & & & \\
\hline & Model & $Y=-.011 x+-.06 y+-.002$ & $Y=-.019 x+-.166 y+-.002$ & $Y=-.066 x+-.014 y+.001$ & $Y=-.005 x+-.061 y+.000$ \\
\hline & $\begin{array}{l}\text { Predicted } \\
\mathrm{Y}\end{array}$ & -.073 & -.188 & -.081 & -.066 \\
\hline \multirow[t]{6}{*}{ Mondays } & Constant & $-.005 * * *$ & $-.012 * * *$ & $-.007 * *$ & .002 \\
\hline & Predictor & $-.039 * * *$ & -.021 & -.169 & $-.016 * *$ \\
\hline & Lag FX & $-.127 *$ & $-.212^{*}$ & .108 & -.161 \\
\hline & Returns & & & & \\
\hline & Model & $Y=-039 x+-.127 y+-.005$ & $Y=.021 x+-.212 y+-.012$ & $Y=-.169 x+.108 y+-.007$ & $Y=-.016 x+-.16 y+.002$ \\
\hline & $\begin{array}{l}\text { Predicted } \\
\text { Y }\end{array}$ & -.171 & -.245 & -.068 & -.175 \\
\hline \multirow[t]{6}{*}{ Tuesdays } & Constant & $-.004 * * *$ & $-.006^{*}$ & $-.009 * *$ & .002 \\
\hline & Predictor & $.033 * * *$ & $-.051 * *$ & -.108 & $-.011 *$ \\
\hline & Lag FX & -.048 & -.187 & -.098 & -.074 \\
\hline & Returns & & & & \\
\hline & Model & $Y=-.033 x+-, 048 y+-.004$ & $Y=-.051 x+-.187 y+-.006$ & $Y=-.108 x+-.098 y+-.009$ & $Y=.011 x+-.074 y+.002$ \\
\hline & $\begin{array}{l}\text { Predicted } \\
\mathrm{Y}\end{array}$ & -.085 & -.244 & -.215 &.-.083 \\
\hline \multirow[t]{6}{*}{ Wednesdays } & Constant & $-.005 * * *$ & $-.009 * * *$ & -.006 & -.001 \\
\hline & Predictor & $-.036 * * *$ & $-.031 * *$ & -.202 & $-.023 * * *$ \\
\hline & Lag FX & $-.012 *$ & $-.324 * * *$ & .069 & $-.126^{*}$ \\
\hline & Returns & & & & \\
\hline & Model & $Y=-.036 x+-.012+-.005$ & $Y=-.031 x+-.324 y+-.009$ & $Y=-.202 x+.069 y+-.006$ & Y-.023x+-.126y+-.001 \\
\hline & $\begin{array}{l}\text { Predicted } \\
\text { Y }\end{array}$ & -.053 & -.364 &.- .139 & -.15 \\
\hline \multirow[t]{6}{*}{ Thursdays } & & $-.005 * * *$ & $-.012 * * *$ & -.008 & .000 \\
\hline & Constant & $-.038 * * *$ & -.019 & -.250 & $-.020 * * *$ \\
\hline & Predictor & $-.118 *$ & $-.309 * * *$ & -.150 & -.090 \\
\hline & Lag FX & & & & \\
\hline & Returns & $Y=-.038 x+-.118 y+-.005$ & $Y=-.019 x+-.309+-.012$ & $Y=-.250 x+-.150 y+-.008$ & $Y=-.020 x+-.09 y+.000$ \\
\hline & $\begin{array}{l}\text { Model } \\
\text { Predicted } \\
\text { Y }\end{array}$ & -.161 & -.340 & -.408 & -.11 \\
\hline \multirow[t]{7}{*}{ Fridays } & & $-.005 * * *$ & $-.008 * * *$ & -.006 & .000 \\
\hline & Constant & $-.034 * * *$ & $-.027 *$ & -.278 & $-.020 * * *$ \\
\hline & Predictor & -.063 & $-.194 * *$ & .178 & $-.110^{*}$ \\
\hline & Lag FX & & & & \\
\hline & Returns & $Y=.034 x+-.063 y+-.005$ & $Y=-.027 x+-.194 y+-.008$ & $Y=-.278 x+.178+-.006$ & $Y=-.020 x+-.11 y+.000$ \\
\hline & Model & -.102 & -.229 & -.106 & -.130 \\
\hline & Predicted & & & & \\
\hline \multirow[t]{8}{*}{ Weekends } & $\mathrm{Y}$ & $-.003 * * *$ & $-.006 * * *$ & $-.004 *$ & .001 \\
\hline & & $-.023 * * *$ & $-.024 * *$ & -.150 & $-.009 * * *$ \\
\hline & Constant & $-.134 * * *$ & $-.242 * * *$ & $-.254 *$ & $-.096^{*}$ \\
\hline & Predictor & & & & \\
\hline & Lag FX & $Y=-.023 x+-.134 y+-.003$ & $Y=-.024 x+-.242 y+-.006$ & $Y=-.150 x+-.254 y+-.004$ & $Y=-.009 x+-.096 y+.00$ \\
\hline & Returns & -160 & -.272 & -.408 & -.104 \\
\hline & Model & & & & \\
\hline & Predicted & & & & \\
\hline
\end{tabular}




\begin{tabular}{|c|c|c|c|c|c|}
\hline \multirow{7}{*}{$\begin{array}{l}\text { Beginning } \\
\text { Of Day }\end{array}$} & Y & $.000 * * *$ & $.000 * *$ & .000 & .0001 \\
\hline & & $-.001 * * *$ & $-.002 * * *$ & $-.010 * *$ & $.000 * * *$ \\
\hline & Constant & .000 & -.013 & -.008 & .002 \\
\hline & Predictor & $Y=-.001 x+.000 y+.000$ & $Y=-.002 x+-.013 y+.000$ & $Y=-.010 x+-.008 y+.000$ & $Y=.000 x+.002 y+.000$ \\
\hline & Lag FX & -.001 & -.0152 & -.018 & .0021 \\
\hline & Returns & & & & \\
\hline & Model & & & & \\
\hline \multirow{8}{*}{$\begin{array}{l}\text { Middle } \\
\text { Of Day }\end{array}$} & Predicted & $.000 * * *$ & $.000 * *$ & .000 & .000 \\
\hline & $\mathrm{Y}$ & $-.001 * * *$ & $-.002 * * *$ & $-.010 * *$ & $-.001 * * *$ \\
\hline & & $-.016^{*}$ & $-.050 * * *$ & -.010 & -.010 \\
\hline & Constant & & & & \\
\hline & Predictor & $Y=-.001 x+-.016 y+.000$ & $Y=-.002 x+-.050 y+.000$ & $Y=-.010 x+-.010 y+.000$ & $Y=-.001 x+-.01 y+.000$ \\
\hline & Lag FX & -.017 & -.052 & -.020 & -.011 \\
\hline & Returns & & & & \\
\hline & Model & & & & \\
\hline \multirow{7}{*}{$\begin{array}{l}\text { End } \\
\text { Of Day }\end{array}$} & Predicted & $.000 * * *$ & $.000 * * *$ & $.000 * *$ & .000 \\
\hline & $\mathrm{Y}$ & $-.001 * * *$ & $-.002 * * *$ & -.005 & $-.001 * * *$ \\
\hline & & $-.018 *$ & $-.048 * *$ & -.025 & -.009 \\
\hline & Constant & $Y=-.001 x+-.018 y+.000$ & $Y=-.002 x+-.048 y+.000$ & $Y=-.005 x+-.025 y+.000$ & $Y=-.001 x+-.009 y+.00$ \\
\hline & Predictor & -.019 & -.050 & -.030 & -.010 \\
\hline & Lag $\mathrm{FX}$ & & & & \\
\hline & Returns & & & & \\
\hline \multirow{10}{*}{$\begin{array}{l}\text { Non-Farm } \\
\text { Payrolls }\end{array}$} & Model & $-.007 * * *$ & $-.018 * *$ & -.007 & -.003 \\
\hline & Predicted & $-.050 * * *$ & -.016 & -.535 & $-.037 * *$ \\
\hline & $\mathrm{Y}$ & -.098 & $-.330 * *$ & .020 & -.120 \\
\hline & Constant & $Y=-.050 x+-.098 y+-.007$ & $Y=-.016 x+-.330 y+-.018$ & $Y=-.535 x+.020 y+-.007$ & $Y=-.037 x+-.12 y+-.003$ \\
\hline & Predictor &.- .155 & -.364 & -.522 & -.160 \\
\hline & Lag FX & & & & \\
\hline & Returns & & & & \\
\hline & Model & & & & \\
\hline & Predicted & & & & \\
\hline & Y & & & & \\
\hline
\end{tabular}

This table reports the regression analysis for various intervals and within three predefined buckets including Lag FX Returns as an additional control. The reported values for the Constant (Intercept), Predictor (gradient), Lag FX Returns (control), Model (Regression Line), and Predicted Y are shown. The buckets are defined as follows: Bucket $1=$ LOGB-LOGS $>0$, Bucket $2=$ LOGB-LOGS $=0$ (300<LOGB-LOGS>-300), and Bucket $3=$ LOGB-LOGS $<0$. LOGB_LOGS (independent variable) is defined as the log transformation of the previous day lag Sell Volume minus the previous day lag Buy Volume. Returns (dependent variable) are defined as the difference between the price from period 1 to period 2 and then subtracting 1 from the difference. Lag FX Returns (control variable) is the previous lag Returns for the current period. Each period is defined as: Daily (from day-to-day), Mondays (only), Tuesdays (only), Wednesdays (only), Thursdays (only), Fridays (only), Weekends (Friday to Sunday only), Beginning of the Day (0000-0759 only), Middle of the Day (0800-1559 only), End of the Day (1600-2359 only), and Non-Farm Payrolls (Thursday-Friday only) on days of release. Significance levels are reported as: *, **, *** .05, .01 and .001 levels, respectively.

Table 4 summarizes the values for the Constant (Intercept), Predictor (gradient), Lag FX Returns (control variable), Model (Regression Line), and the Predicted value of Y for the regression between Returns, the log transformation of the previous day's Buy Volume minus the log transformation of the previous day's Sell Volume (LOGB_LOGS), and the lag foreign exchange returns (LagFXReturn) by one period (daily).

We find regressions between Returns, LOGB_LOGS, and LagFXRetruns are all negative, except for one period (Beginning of the Day, Bucket 3). The findings are not unexpected and generally fall in line with previous expectations. However, we do find that adding the control variable does detract from the significance levels of the regressions, indicating that our volume effects are capturing some of this momentum effect. This suggests that momentum effects do make a difference, but they are not significantly affecting Returns in our main findings.

Volume tends to be persistent in our data set (Anderson and Bollerslev, 1997). In order to determine if unexpected volumes matter, we run a simple regression where we regress current volumes against lagged volumes and analyze the residuals. 
Table 5. Residual Statistics

\begin{tabular}{lllll}
\hline & Min & Max & Mean & Std Deviation \\
\cline { 2 - 5 } Variables & & & & \\
& & & & \\
Predicted Value & 3821.34 & 35140.31 & 13918.66 & 5929.913 \\
Std. Predicted Value & -1.703 & 3.579 & .000 & 1.00 \\
Standard Error of Predicted & & & & \\
Value & 20.951 & 77.868 & 28.944 & 6.339 \\
Adjusted Predicted Value & 3820.68 & 35142.42 & 13918.73 & 5930.047 \\
Residual & -18044.9 & 6947.78 & .000 & 956.661 \\
Std. Residual & -18.858 & 7.261 & .000 & 1.00 \\
Stud. Residual & -18.903 & 7.267 & .000 & 1.001 \\
Deleted Residual & -18130.8 & 6959.12 & -.071 & 958.195 \\
Stud. Deleted Residual & -20.762 & 7.359 & -.001 & 1.019 \\
Mahal. Distance & .000 & 12.807 & 1.00 & 1.032 \\
Cook's Distance & .000 & .850 & .001 & .019 \\
Centered Leverage Value & .000 & .006 & .000 & .000 \\
\hline
\end{tabular}

This table presents residual statistics on daily EUR-USD spot exchange rates from Forex Capital Markets (FXCM) over January 3, 2007 through June 4, 2015 sample period. We did a simple regression regressing current volumes against lagged volumes (one period). The residual statistics are below and include the Minimum Value (Min), Maximum Value (Max), Mean, and Standard Deviation (Std. Deviation) for the following: Predicted Value, Standardized Predicted Value (Std. Predicted Value), Standard Error of Predicted Value, Adjusted Predicted Value, Residual, Standardized Residual (Std. Residual), Studentized Residual (Stud. Residual), Deleted Residual, Studentized Deleted Residual (Stud. Deleted Residual), Mahalanobis Distance (Mahal. Distance), Cook's Distance, and the Centered Leverage Value. The data reflects 2086 observations with bias corrected accelerated bootstrap at 95\% Confidence Intervals.

Visual inspection of the scatterplots of the standardized residuals (current volume) against predicted (fitted) values (lagged volume) of the residuals give us an indication of linearity or homoscedasticity. We find the scatterplots are normal looking and show no visible pattern in which the assumptions of linearity and homoscedasticity have not been met. While there is a large number of plots in the center, the scatterplot does not indicate heteroscedasticity, non-linearity or heteroscedasticity and non-linearity.

We also observe that the P-P plots show both variables (current volume and lagged volume) are normally distributed. In our attempts to determine if the unexpected volumes matter, we find no indication that the current volume is significantly different than the lagged volume, as they are very highly correlated (Pearson's correlation coefficient $=.987$ ). Therefore, we conclude that it is not necessarily the unexpected volume that is impacting the results, as it is the volume (in general).

As an additional measure, we look to see if the buy-sell volume is related to another potential variable. Due to the unique nature of measured volume, interest rates are the only viable variable we can test given the daily frequency of the data set. We take the daily interest rate yield on the US Treasury Securities at 1 month constant maturity, quoted on investment basis from the Board of Governors of the Federal Reserve (www.federalreserve.gov) and run a correlation analysis between the simple difference in the change of the daily interest rate and the difference between the log transformation of the Buy Volume minus the log transformation of the Sell Volume (LOGB_LOGS). 
Table 6. Correlation Analysis for LOGB_LOGS and the Change in Daily Interest Rates

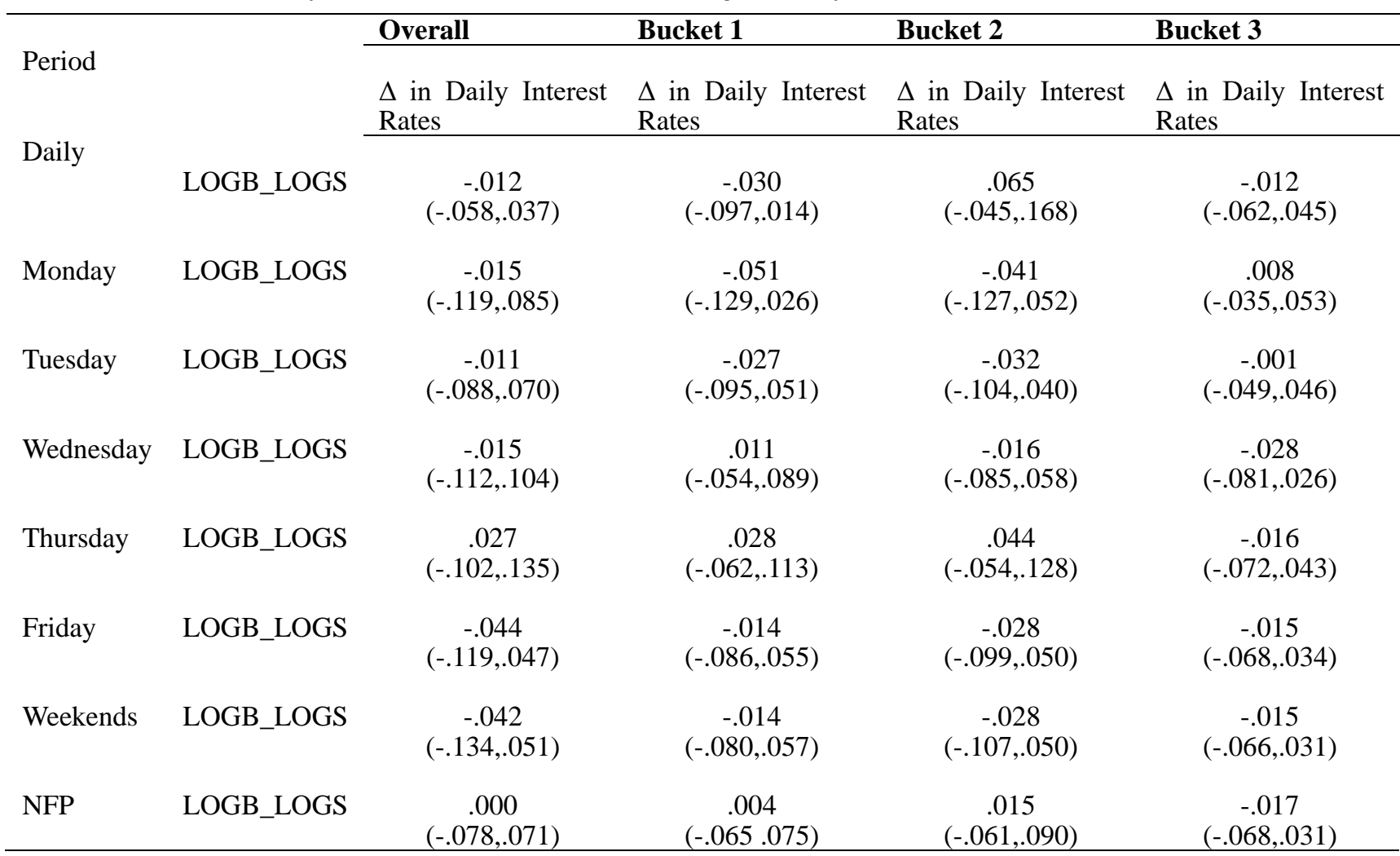

This table reports Pearson's correlation coefficient between LOGB_LOGS and the Change in Daily Interest Rates for various intervals and within three predefined buckets. The buckets are defined as follows: Bucket $1=$ LOGB-LOGS $>0$, Bucket $2=$ LOGB-LOGS $=0$ (300<LOGB-LOGS>-300), and Bucket $3=$ LOGB-LOGS < 0. LOGB_LOGS is defined as the log transformation of the previous day lag Buy Volume minus the previous day lag Sell Volume. The Change in Daily Interest Rates is defined as the Current Daily Interest Rate minus the previous Daily Interest Rate. Each period is defined as: Daily (from day-to-day), Mondays (only), Tuesdays (only), Wednesdays (only), Thursdays (only), Fridays (only), Weekends (Friday to Sunday only), and Non-Farm Payrolls (NFP) (Thursday-Friday only) on days of release. Significance levels are reported as: *,**,***.05, .01 and .001 levels, respectively. Bias corrected accelerated bootstrap 95\% Confidence Intervals reported in the parentheses.

We define the simple difference in the change of the daily interest rate as:

$$
I R_{t}=i r_{t}-i r_{t-1}
$$

where the interest rate difference from day $t-1$ to $t$ are computed. $I R_{t}$ is the difference in interest rate at the daily close where the daily interest rate $t$ is $i r_{t}$, and the daily interest rate at the daily close $t-l$ is $i r_{t-1}$.

Table 6 summarizes the Pearson's correlation coefficient for the defined intervals. We separate each interval into the overall correlation, then the predefined buckets and report the coefficient. We find the correlation between the simple difference in the change of the daily interest rate and LOGB_LOGS are split between positive and (mostly) negative. None of the correlation coefficients are significant. The lack of significant correlation coefficients suggest no correlation in the simple difference in the change of the daily interest rates and the difference in buy volume and sell volume. This finding gives credibility to spectators focusing on technical trading strategies vs. fundamental trading strategies (Taylor and Allen, 1992; Sweeney, 1986; Neely, Weller, and Ditmar, 1997). ${ }^{1}$

\section{Conclusion}

We show that lag Volume contains unique information when compared to current Returns in the Euro-Dollar market that has not been captured in previous works. Using a unique set of data from FXCM from January 3, 2007 to June 4, 2015, we find that the log transformation of the previous day's Buy Volume minus the log transformation of the previous day's Sell Volume is inversely related to current Returns. This unique market information on lag Volume and current

\footnotetext{
${ }^{1}$ When we interact volume signals with interest rate fundamentals, we find that the constant and the log transformation of the buy volume minus the log transformation of the sell volume remain significant, while the additional variable interaction of interest rate times volume is insignificant.
} 
Returns is counter-intuitive, and falls in line with common thought on observed market inefficiencies and investor irrationality (Shiller, 1989). After exploring different calendar effects, we find that lag Volume significantly predicts current Returns.

We also highlight a trading strategy based on the inverse relationship between the log transformation of the previous day's Buy Volume minus the log transformation of the previous day's Sell Volume and current Returns. By dividing the data into two sub-groups (of approximately 4 years each), we use the first sub-group to develop the strategy, and the second sub-group to test it. We show that by using the relationship between lag Volume and current Returns, the strategy yields in excess of 5000 pips over the course of the second sub-group (approximately 4 years). Economically, the value of one standard lot is approximately $\$ 2400$ (US dollars) which over the course of 4 years (second sub-group) exceeds the value of $\$ 50,000$ (US dollars) following the strategy. Naturally, the equity curve does not go straight up, but rather follows acceptable ebbs and flows of the market (with slight drawdowns). Our findings are in line with previous literature on profitable trading strategies, but we differentiate our strategy by focusing on Buy/Sell Volume differentials in predicting Returns in line with behavioral finance and the irrationality of investors. ${ }^{2}$

\section{References}

Andersen, T. G., \& Bollerslev, T. (1997). Intraday Periodicity and Volatility Persistence in Financial Markets. Journal of Empirical Finance, 4, 115-158. https://doi.org/10.1016/S0927-5398(97)00004-2

Brock, W., Lakonishok, J., \& LeBaron, B. (1992). Simple Technical Trading Rules and the Stochastic Properties of Stock Returns. Journal of Finance, 47, 1731-1764. https://doi.org/10.1111/j.1540-6261.1992.tb04681.x

Chan, K., \& Fong, W. M. (2000). Trade size, order imbalance, and the volatility-volume relation. Journal of Financial Economics, 57(2), 247-273. https://doi.org/10.1016/S0304-405X(00)00057-X

Chiang, T., \& Jiang, C. (1995). Foreign Exchange Returns Over the Short and Long Horizons. International Review of Economics and Finance, 4, 267-282. https://doi.org/10.1016/1059-0560(95)90044-6

Dacorogna, M. M., Muller, U. A., Nagler, R. J., Olsen, R. B., \& Pictet, O. V. (1993). A Geographical Model for Daily and Weekly Seasonal Volatility in the Foreign Exchange Market. Journal of International Money and Finance, 12, 413-438. https://doi.org/10.1016/0261-5606(93)90004-U

Dooley, M. P., \& Shafer, R. J. (1983). Analysis of Short-Run Exchange Rate Behavior: March 1973 to November 1981. In Exchange Rate and Trade Instability: Causes, Consequences, and Remedies, D. Bigman and T. Taya, eds. Cambridge, MA: Ballinger.

Engel, C., \& Hamilton, J. (1990). Long Swings in the Dollar: Are they in the data, and do the markets know it? The American Economic Review, 80, 689-713.

Fama, E. (1965). The Behavior of Stock Market Prices. Journal of Political Economy, 38, 34-105. https://doi.org/10.1086/294743

Fama, E. (1984). Forward and Spot Exchange Rates. Journal of Monetary Economics, 14, 319-338. https://doi.org/10.1016/0304-3932(84)90046-1

Froot, K. A., \& Ramadorai, T. (2005). Currency Returns, Intrinsic Value, and Institutional-Investor Flows. Journal of Finance, 60, 1535-1566. https://doi.org/10.1111/j.1540-6261.2005.00769.x

Harris, L. (1987). Transaction Data Tests of the Mixture of Distributions Hypothesis. Journal of Financial and Quantitative Analysis, 22(20), 127-141. https://doi.org/10.2307/2330708

Kaniel, R., Saar, G., \& Titman, S. (2008). Individual Investor Trading and Stock Returns. Journal of Finance, 63, 273-310. https://doi.org/10.1111/j.1540-6261.2008.01316.x

Khemiri, R. (2012). Volume and Volatility in the Foreign Exchange Market Microstructure: A Markov Switching Approach. Applied Financial Economics, 22, 1121-1133. https://doi.org/10.1080/09603107.2011.629979

Lee, C. M., \& Radhakrishna, B. (2000). Inferring investor behavior: Evidence from TORQ data. Journal of Financial Markets, 3(2), 83-111. https://doi.org/10.1016/S1386-4181(00)00002-1

Lee, C. M., \& Ready, M. (1991). Inferring Trade Directions from Intraday Data. Journal of Finance, 46, 733-746. https://doi.org/10.1111/j.1540-6261.1991.tb02683.x

Llorente, G., Michaely, R., Saar, G., \& Wang, J. (2002). Dynamic volume-return relation of individual stocks. Review of

${ }^{2}$ Optimal lag length is chosen using the Schwarz Information Criterion (SIC). The optimal lag length is a one period lag (starting with a maximum of fifteen lags) as reported in the analysis, and is confirmed by profitability as determined by the net number of pips gained (i.e. in excess of 5000 pips over the course of the second sub-group). 
Financial Studies, 15(4), 1005-1047. https://doi.org/10.1093/rfs/15.4.1005

Lyons, R. K. (1995). Tests of Microstructural Hypotheses in the Foreign Exchange Market. Journal of Financial Economics, 39, 321-351. https://doi.org/10.1016/0304-405X(95)00832-Y

Marsh, I. W. (2000). High-Frequency Markov Switching Models in the Foreign Exchange Market. Journal of Forecasting, $19(2)$ 123-134. https://doi.org/10.1002/(SICI)1099-131X(200003)19:2<123::AID-FOR750>3.0.CO;2-C

Menkoff, L., Sarno, L., Schmeling, M., \& Schrimpf, A. (2016). Information flows in Foreign Exchange Markets: Dissecting Customer Currency Trades. Journal of Finance, 71(2), 601-634. https://doi.org/10.1111/jofi.12378

Muller, U. A., Dacorogna, M. M., Olsen, R. B., Pictet, O. V., Schwarz, M., \& Morgenegg, C. (1990). Statistical Study of Foreign Exchange Rates, Empirical Evidence of a Price Change Scaling Law and Intraday Analysis. Journal of Banking of Finance, 14, 1189-1208. https://doi.org/10.1016/0378-4266(90)90009-Q

Neely, C., Weller, P., \& Dittmar, R. (1997). Is Technical Analysis in the Foreign Exchange Market Profitable? A Genetic Programming Approach. The Journal of Financial and Quantitative Analysis, 32(4), 405-426. https://doi.org/10.2307/2331231

Okunev, J., \& White, D. (2003). Do Momentum-Based Strategies Still Work in the Foreign Currency Markets? Journal of Financial and Quantitative Analysis, 38, 425-447. https://doi.org/10.2307/4126758

Schumpeter, J. (1954). History of Economic Analysis. New York: Oxford University Press.

Shiller, R. J. (1989). Investor Behavior in the October 1987 Stock Market Crash: Survey Evidence.

Shleifer, A., \& Summers, L. H. (1990). The Noise Trader Approach to Finance. Journal of Economic Perspectives, 4, 19-33. https://doi.org/10.1257/jep.4.2.19

Sweeney, R. J. (1986). Beating the Foreign Exchange Market. The Journal of Finance, 41(1), 163-182. https://doi.org/10.1111/j.1540-6261.1986.tb04497.x

Sweeney, R. J. (1997). Do Central Banks Lose on Foreign Exchange Intervention? A Review Article. Journal of Banking and Finance, 21, 1667-1684. https://doi.org/10.1016/S0378-4266(97)00033-2

Taylor, M. P., \& Allen, H. (1992). The Use of Technical Analysis in the Foreign Exchange Market. Journal of International Money and Finance, 11, 304-314. https://doi.org/10.1016/0261-5606(92)90048-3

Wasserfallen, W. (1989). Flexible Exchange Rates: A Closer Look. Journal of Monetary Economics, 23, 511-521. https://doi.org/10.1016/0304-3932(89)90044-5

Weber, M. (1999). Behavioral Finance. Research for Practitioners, 8, University of Mannheim.

\section{Copyrights}

Copyright for this article is retained by the author(s), with first publication rights granted to the journal.

This is an open-access article distributed under the terms and conditions of the Creative Commons Attribution license which permits unrestricted use, distribution, and reproduction in any medium, provided the original work is properly cited. 